\title{
Stress responses of juvenile brown trout under winter conditions in a laboratory stream
}

\author{
Johan Watz $(\mathbb{D}$
}

Received: 6 September 2016/Revised: 5 April 2017/Accepted: 21 May 2017/Published online: 29 May 2017

(C) The Author(s) 2017. This article is an open access publication

\begin{abstract}
Winter can be a challenging period for fish in northern temperate rivers and streams, particularly in those that are channelized, structurally simple or regulated by, for instance, hydropower. In these systems, dynamic sub-surface ice formation commonly occurs and stable periods with ice cover may be short. Under these adverse conditions, access to shelters has been shown to be an important factor that influences overwinter survival, and exclusion from shelters by anchor ice may cause stress. Here, stress responses of juvenile brown trout under simulated winter conditions in an artificial stream were studied. Trout were subjected to three treatments in which the trout (1) were excluded from an instream wood shelter, simulating the effects of anchor ice, (2) had access to the shelter or (3) had surface ice cover in addition to the shelter. There was a positive correlation between ventilation frequency and plasma cortisol concentration. Trout without access to shelter had 30\% higher ventilation frequency than trout with instream shelter
\end{abstract}

Electronic supplementary material The online version of this article (doi:10.1007/s10750-017-3246-8) contains supplementary material, which is available to authorized users.

Handling editor: Ingeborg Palm Helland

J. Watz $(\bowtie)$

River Ecology and Management Group, Department of Environmental and Life Sciences, Karlstad University, Universitetsgatan 2, 65188 Karlstad, Sweden

e-mail: johan.watz@kau.se and surface ice, but no differences in cortisol concentration or stress colour were found between the treatments. River regulation that reduces surface ice and increases anchor ice formation may lead to increased stress and consequently reduce overwinter survival rates.

Keywords Anchor ice · Colour · Cortisol · Ice cover $\cdot$ Salmonid $\cdot$ Ventilation

\section{Introduction}

During winter, ice in boreal rivers and streams affects the environmental conditions for lotic fish (Prowse, 2001). Different types of ice may, however, have opposite effects on behaviour and mortality. For instance, surface ice promotes stability of the physical stream environment (e.g., constant temperature and low light levels; Hansen and Rahel, 2015) and reduces predation risk from terrestrial piscivores (Linnansaari \& Cunjak, 2010; Hedger et al., 2013; Watz et al., 2013). In contrast, ice formation in the water column results in frazil ice that adheres to instream surfaces and may continue to grow as anchor ice on the stream bottom (Stickler \& Alfredsen, 2009). This type of ice may fill crevices and cover stream wood, thereby excluding fish from these winter shelters (Brown \& Mackay, 1995; Jakober et al., 1998).

In regulated rivers, warm hypolimnetic water released from dams at, for instance, hydroelectric 
powerplants and fluctuating discharges reduce periods with stable ice cover and make the ice formation and breakup processes more dynamic (Ugedal et al., 2008; Gebre et al., 2013). Cold spells may result in substantial frazil and anchor ice formation in these rivers (Timalsina et al., 2013), and in the absence of ice cover, frazil and anchor ice may form during freeze-up periods throughout the whole winter (Stickler \& Alfredsen, 2009). In extreme cases, anchor ice blankets the entire stream bottom, altering stream hydraulics and making interstitial spaces on the stream bottom inaccessible for fish. Therefore, the contrast in ice conditions, and thus the physical winter environment for stream fish, may be large between an unregulated, stable, ice covered river and a regulated river with dynamic instream ice formation.

It is possible that lack of refuges is particularly stressful during winter, because low water temperatures impair the swimming capacity of the fish, reducing their ability to escape predators (Huusko et al., 2007). Juvenile salmonids seem to cope relatively well with low temperatures and river ice formation per se (Linnansaari \& Cunjak, 2013), but lack of access to shelters against predation from endothermic piscivores may lead to stress (Finstad et al., 2007; Watz et al., 2015) and has shown to be a major factor that influences overwinter mortality (Huusko et al., 2007; Brown et al., 2011).

Fish respond to stress by altering their behaviour and physiology to maintain homeostasis (Bonga, 1997). Primary stress responses include elevated hormonal levels of corticosteroids (e.g., cortisol) and catecholamines and changes in neurotransmitter activity (Barton, 2002). If stressors (real or perceived) are long-lasting, repeated or severe, secondary stress responses (i.e., alterations in the metabolism, osmoregulation, haematological profile and immune system) may induce whole-animal responses, such as reduced well-being and altered behaviour and growth patterns (Barton \& Schreck, 1987; Barton \& Iwama, 1991; Espelid et al., 1996; McCormick et al., 1998). Although the structure of primary, secondary and whole-animal responses suggests causality between the levels of organisation, different stressors may, however, induce responses that can be measured only at some levels (Barton, 2002). Therefore, depending on the type of stressor and its magnitude, some measures of stress might be more sensitive and thus more suitable than others.
To assess the importance of shelter availability for the stress level of overwintering salmonids, both the primary, secondary and whole-animal responses can be measured. One drawback of measuring primary and secondary stress responses is that these measurements often are invasive. Several non-invasive observational methods exist to assess whole-animal stress responses, for example measuring ventilation frequency (a proxy for oxygen consumption and metabolic rate) and eye and body darkening (O'Connor et al., 1999; Höglund et al., 2000; Hawkins et al., 2004; Millidine et al., 2008; Freitas et al., 2014). Yet, direct observations of salmonids under winter conditions are rare. This study explores the stress response of overwintering juvenile brown trout (Salmo trutta L.) subjected to different ice conditions that might occur in a natural stream during winter. Specifically, individual trout were subjected to three treatments in a laboratory stream, where trout (1) were excluded from an instream wood shelter (simulating the effect of anchor ice), (2) had access to the bottom shelter and (3) had access both to bottom shelter and partial surface ice cover. Ventilation frequency, plasma cortisol concentration and eye and body colour were measured and compared between the treatments. In addition, the relationships between these measurements were assessed.

\section{Materials and methods}

Fish

One-summer-old hatchery reared brown trout (first generation from wild parents with origin from River Gullspång, Sweden) were sourced from Gammelkroppa Lax hatchery and brought to the aquarium facility at Karlstad University. Trout were acclimated to laboratory conditions for approximately one month before the experiment. In the experiment, 18 trout were used (mean length and mass \pm 1 SD: $119 \pm 14 \mathrm{~mm}$ and $17.2 \pm 5.6 \mathrm{~g}$ ). Trout were randomly assigned to one of the three treatment groups and tested in random order, resulting in six trout subjected to each treatment. There was no difference in length or mass between the treatment groups (ANOVA; length $F_{2,15}=0.27, \quad P=0.97$; mass $\left.F_{2,15}=0.52, P=0.95\right)$. 
Stream tank

In a 7-m-long laboratory stream (c. $4 \mathrm{~m}^{3} ; 81 \mathrm{~s}^{-1}$ ), an experimental area measuring $1.2 \times 0.7 \mathrm{~m}$ was created. The arena consisted of two equal-sized areas; one upstream and one downstream section (depths $=0.2$ and $0.4 \mathrm{~m}$; water velocities at 0.6 of the depth $=7$ and $3 \mathrm{~cm} \mathrm{~s}^{-1}$ at 0.12 and $0.24 \mathrm{~m}$ depth, respectively). Photoperiod was set to 12:12 h (light:darkness), which corresponds to the photoperiod of mid-March in central Sweden. The arena could be observed through a glass window in simulated daylight (light intensity at the surface $=7001 \mathrm{x})$, and in darkness $(<0.1 \mathrm{~lx})$ infrared lamps and an infrared-sensitive video camera were used (Watz et al. 2013, 2014). Gravel (diameter $=1-3 \mathrm{~cm}$ ) covered the bottom. In the downstream section, a bundle of fine birch wood (diameter $=1-2 \mathrm{~cm}), \quad$ measuring $35 \times 20 \times 10 \mathrm{~cm}$ $(1 \times \mathrm{w} \times \mathrm{h}$ ), was placed on the bottom (Fig. 1). The wood bundle was loosely packed, offering juvenile trout shelter inside the bundle. Water temperature was maintained at $2^{\circ} \mathrm{C}$ throughout the experiment, regardless of treatment.

\section{Treatments}

Treatments used in the study were selected to simulate three winter conditions in relation to shelter availability and stream ice: (1) exclusion from the bottom shelter by simulated anchor ice, (2) access to the bottom shelter and (3) partial surface ice cover in addition to access to the bottom shelter (Fig. 2).

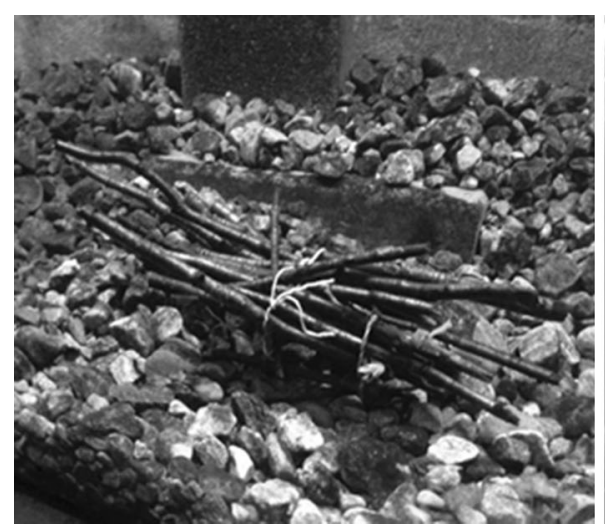

Fig. 1 Juvenile brown trout (Salmo trutta) were observed under winter conditions in an artificial stream. In treatments where trout had access to a wood bundle shelter in the deep
Because anchor ice does not form underneath an ice cover (Stickler \& Alfredsen, 2009), the treatment with both simulated anchor ice and surface ice was not included. In treatment (1), a white, fine-meshed net $(40 \times 30 \mathrm{~cm})$ was placed over the fine wood bundle to simulate the excluding effect of anchor ice on shelter access (Fig. 1). In treatment (2), no surface ice or net were used. In treatment (3), a 6-cm-thick ice block $(0.7 \times 0.6 \mathrm{~m})$, created by freezing distilled water in a plastic tray (Dilling, IKEA AB, Älmhult, Sweden), was suspended by concrete blocks near the surface (Watz et al., 2015), covering the deep section of the arena. Thus, in the treatment without ice (2) and in the surface ice treatment (3), trout had access to the instream wood shelter. Surface ice reduced light intensity from 500 to $300 \mathrm{~lx}$ at the bottom of the deep section, light levels that both correspond to an overcast day. In the range from 300 to $5001 \mathrm{x}$, the effects of light level on the behaviour of salmonids is very small or non-existing (Valdimarsson \& Metcalfe, 2001),

\section{Experimental protocol}

The trials were run in April, 2016. The day before a trial at 12:00, a randomly selected trout was transferred from its holding tank to the experimental arena. Approximately, $1 \mathrm{~h}$ before the light was turned on at 09:00, resting ventilation frequency was measured in darkness, by using infrared cameras and lamps to record resting trout and counting the number of beats per $30 \mathrm{~s}$ three times. Although these three measures of ventilation frequency were nearly identical, it is

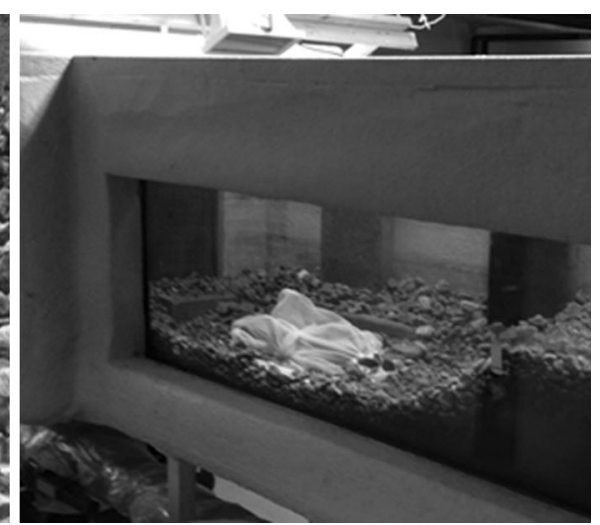

section (left photograph), this shelter was used by all except one trout. A net placed over the wood bundle simulated the effect of shelter exclusion by anchor ice (right photograph) 


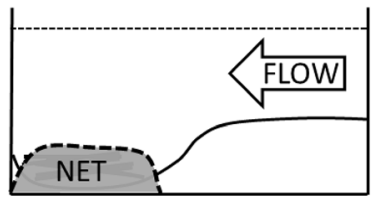

Anchor ice

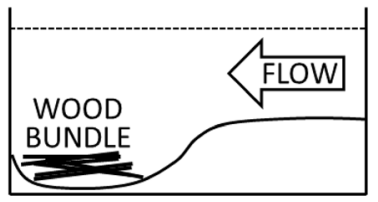

No ice

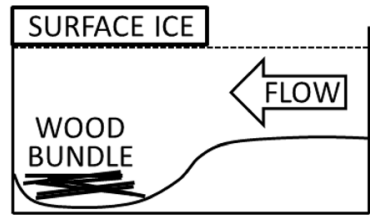

Surface ice
Fig. 2 The three treatments used in the experiment. A finemeshed net was placed over a wood bundle in the anchor ice treatment to simulate the excluding effect of anchor ice on shelter access. In the no ice treatment, the wood bundle was

possible that behaviour prior to measuring ventilation frequency would result in elevated frequencies. Therefore, the median values of the three measured were used in the analysis (Watz et al., 2013). For trials with surface ice, the ice was suspended over the stream tank immediately after measuring resting ventilation frequency (at approximately 08:30), and the ice did not thaw during a trial. For trials without surface ice, a plastic sheet was placed over the tank and then removed to disturb the trout in a similar way as in trials with surface ice. In simulated daylight, approximately at 10:30, the position and swimming activity of the trout was recorded during $10 \mathrm{~min}$, by measuring the time spent in the deep versus the shallow section, the time spent inside the instream wood shelter and the time spent swimming versus resting on the bottom. These measurements were recorded because previous studies have shown effect of stream ice on microhabitat selection and activity (Linnansaari \& Cunjak, 2013; Watz et al., 2016). During this 10 min period, ventilation frequency was measured and eye and body colour were scored according to Watz et al. (2015). In brief, eye colour was assessed from observations and the video recordings and scored on a scale from 1 to 5 , where a score of 1 represents an unstressed trout with pale iris and sclera and a 5 represents a stressed trout with dark iris and sclera. Body colour was scored similarly $(1=$ pale, unstressed; $5=$ dark, stressed $)$ (O'Connor et al., 1999; Suter \& Huntingford, 2002; Watz et al., 2015). After the non-invasive measurements, trout were quickly hand-netted $(<20 \mathrm{~s})$, anesthetised with a lethal dose of benzocaine (completely anaesthetised in $<60 \mathrm{~s}$ ) and killed with a blow to the head. Blood samples were immediately taken by tail ablation, using heparinised haematocrit tubes (diameter $=1 \mathrm{~mm}$ ). The samples were centrifuged, and plasma was frozen and stored at $-20^{\circ} \mathrm{C}$. Before available as an instream shelter. In the surface ice treatment, an ice block was suspended near the surface covering the deep section of the experimental arena, offering cover in addition to the instream wood shelter

analysis, cortisol from $20 \mu \mathrm{l}$ plasma was extracted with $1 \mathrm{ml}$ ethyl acetate and evaporated to dryness. Plasma cortisol concentrations were determined using a competitive conjugated binding ligand by means of an ELISA kit (DE1887; range of detection: 0-800 ng ml; Demeditec Diagnostics GmbH, KielWellsee, Germany) (Velasco-Santamaría \& CruzCasallas, 2007; Ibarra-Zatarain et al., 2016; PinedoGil et al., 2016). The ELISA was carried out in accordance to the manufacturer's protocol.

\section{Statistical analysis}

Individual differences in standard metabolic rate lead to variation in resting ventilation frequency (Millidine et al., 2008). To control for this variation, effects of treatment on ventilation frequency during the trials were analysed using ANCOVA with the resting ventilation frequency in darkness as a covariate. Effects of treatment on cortisol concentration and colour were analysed using ANOVA and KruskalWallis $H$ tests, respectively. The relationships between the four stress measurements (ventilation frequency, cortisol concentration and eye and body colour) were examined using different correlation analyses on data pooled from the three treatments; Pearson correlation was used for the relationship between ventilation frequency and cortisol concentration (continuous data), and Spearman's rank correlation was used for all other relationships (ordinal data). Time (Julian date) did not correlate with any of the response variables (Spearman rank, $n=18$, $P>0.10)$, was found non-significant when included as a covariate in the ANOVA models $(P>0.10)$ and thus not considered further in the analyses. Ventilation frequency and cortisol concentration data satisfied homogeneity of variance requirements (Levene's test: 
$P>0.05)$. Statistical analyses were performed with SPSS Statistics 20 (IMB, Armonk, NY).

\section{Results}

Measured in darkness before the trials, resting ventilation frequency ranged from 29 to 40 beats $\mathrm{min}^{-1}$. There was no difference in resting ventilation frequency between the trout from the different treatments $\left(F_{2,15}=1.63, P=0.23\right)$. During the subsequent trials, most trout positioned themselves motionless on the bottom in the deep section of the testing arena. Two of the 18 trout used the shallow section during part of the observation period. Active swimming in the water column was only observed in four trout. Trout that had access to the instream wood shelter, i.e., trout subjected to the no ice $(n=6)$ or surface ice $(n=6)$ treatment, used this shelter, and only one of these 12 trout was observed resting outside the shelter.

Ventilation frequency, measured in daylight during trials, ranged from 25 to 53 beats $\mathrm{min}^{-1}$. An ANCOVA with resting ventilation frequency measured in darkness used as a covariate revealed that treatment affected mean ventilation frequency (Table 1). Trout excluded from the instream wood shelter had about $20 \%$ higher ventilation frequency than those that had access to the shelter and about $30 \%$ higher ventilation frequency than trout that also had surface ice cover (Fig. 3). Pairwise Bonferroni-corrected post hoc tests showed that trout with both
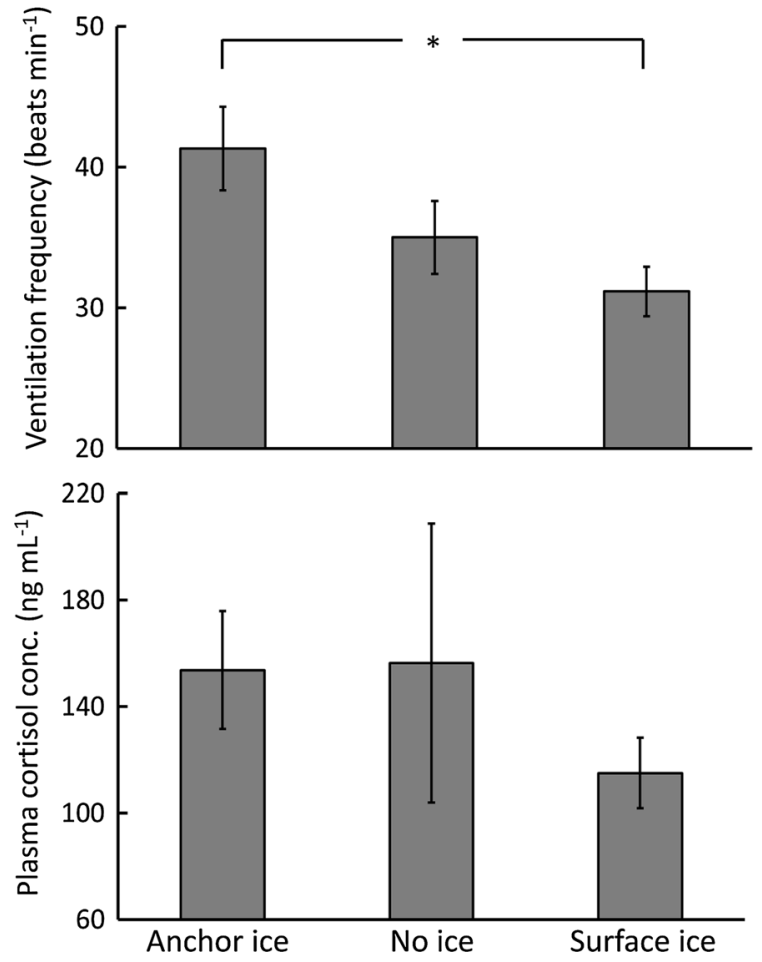

Fig. 3 Juvenile brown trout (Salmo trutta) under simulated winter conditions in an artificial stream were subjected to three treatments where trout were (1) excluded from an instream wood shelter, simulating the effect of anchor ice ("anchor ice"), (2) had access to the instream shelter ("no ice") and (3) had access both to instream shelter and partial ice cover ("surface ice"). Mean ventilation frequency (upper panel) and plasma cortisol concentration (lower panel) were measured $(n=6)$. Asterisk denotes a significant difference $(P<0.05)$ and error bars indicate $\pm 1 \mathrm{SE}$
Table 1 ANCOVA table for the effect of ice treatment on the ventilation frequency of juvenile brown trout (Salmo trutta)

Resting ventilation frequency measured in darkness was used as a covariate

\begin{tabular}{|c|c|c|c|c|c|c|c|}
\hline Source & d.f. & SS & MS & $F$ & $P$ & & $\eta_{\mathrm{p}}^{2}$ \\
\hline Model & 3 & 430.2 & 143.4 & 4.52 & 0.02 & & 0.49 \\
\hline Error & 14 & 444.3 & 31.7 & & & & \\
\hline Corr. total & 17 & 874.5 & & & & & \\
\hline Ice treatment & 2 & 367.6 & 183.8 & 5.79 & 0.015 & & 0.453 \\
\hline Resting ventilation frequency & 1 & 113.9 & 113.9 & 3.59 & 0.079 & & 0.204 \\
\hline Parameter & Estimate & $t$ & $P$ & SE of estimat & & $\eta_{\mathrm{p}}^{2}$ & \\
\hline Intercept & 3.84 & 0.26 & 0.797 & 14.61 & & 0.005 & \\
\hline $\begin{array}{l}\text { Resting ventilation } \\
\text { frequency }\end{array}$ & 0.82 & 1.89 & 0.079 & 0.44 & & 0.204 & \\
\hline Anchor ice & 10.44 & 3.21 & 0.006 & 3.26 & & 0.424 & \\
\hline No ice & 1.50 & 0.43 & 0.673 & 3.48 & & 0.013 & \\
\hline Surface ice & 0 & - & - & - & & - & \\
\hline
\end{tabular}


surface ice and instream shelter had significantly lower ventilation frequency than trout that were excluded from shelter (estimated mean difference $=10.4, \mathrm{SE}=3.3, P=0.019$ ). The ventilation frequency of trout that were excluded from shelter and those of trout with access to shelter (but no surface ice) did not, however, differ significantly (estimated mean difference $=8.9, \mathrm{SE}=3.5, P=0.072$ ). The ventilation frequencies of trout that had both surface ice cover and instream shelter and of those that had access to the instream shelter only were similar (estimated mean difference $=-1.5, \mathrm{SE}=3.5, P=1.0$ ).

Mean plasma cortisol concentration was $143 \mathrm{ng} \mathrm{ml}^{-1}$ and ranged from 48 to $400 \mathrm{ng} \mathrm{ml}^{-1}$. Treatment did not affect mean cortisol concentration $\left(F_{2,15}=0.47, P=0.64, \eta_{\mathrm{p}}^{2}=0.06\right.$; Fig. 3$)$. Trout from the surface ice treatment had the shortest range (62-143 $\mathrm{ng} \mathrm{ml}^{-1}$ ) and the lowest standard deviation $\left(32 \mathrm{ng} \mathrm{ml}^{-1}\right.$ ). Trout without surface ice that were excluded and had access to the shelter, respectively, had the ranges 103-256 and 48-400 $\mathrm{ng} \mathrm{ml}^{-1}$ and the standard deviations 54 and $128 \mathrm{ng} \mathrm{ml}^{-1}$.

Both eye and body colour ranged from fairly light (minimum eye and body scores $=1$ and 2 , respectively) to completely dark (maximum eye and body score $=5$ ). The majority of trout $(78 \%)$ had eye and body scores between 3 and 4, and all of the trout under surface ice had these intermediate colour scores. In contrast, trout with both light and dark colours were found in the two treatments without surface ice (Fig. 4). Treatment did not affect median eye or body colour $\left(\chi^{2}=4.65\right.$ and $1.30, \mathrm{df}=2, P=0.10$ and 0.52 , respectively).

There was a strong positive correlation between ventilation frequency measured during the trials and plasma cortisol concentration $(n=18, R=0.59$, $P=0.009$; Fig. 5). Ventilation frequency or cortisol concentration did not correlate with eye $(n=18$, $U=-0.014$ and $-0.003, P=0.96$ and 0.99 , respectively) or body colour ( $n=18, U=0.021$ and 0.083 , $P=0.94$ and 0.74 , respectively). Eye and body colour were strongly positively correlated $(n=18$, $U=0.59, P=0.010)$.

\section{Discussion}

This study suggests that exclusion from instream cover under winter conditions leads to a stress response in
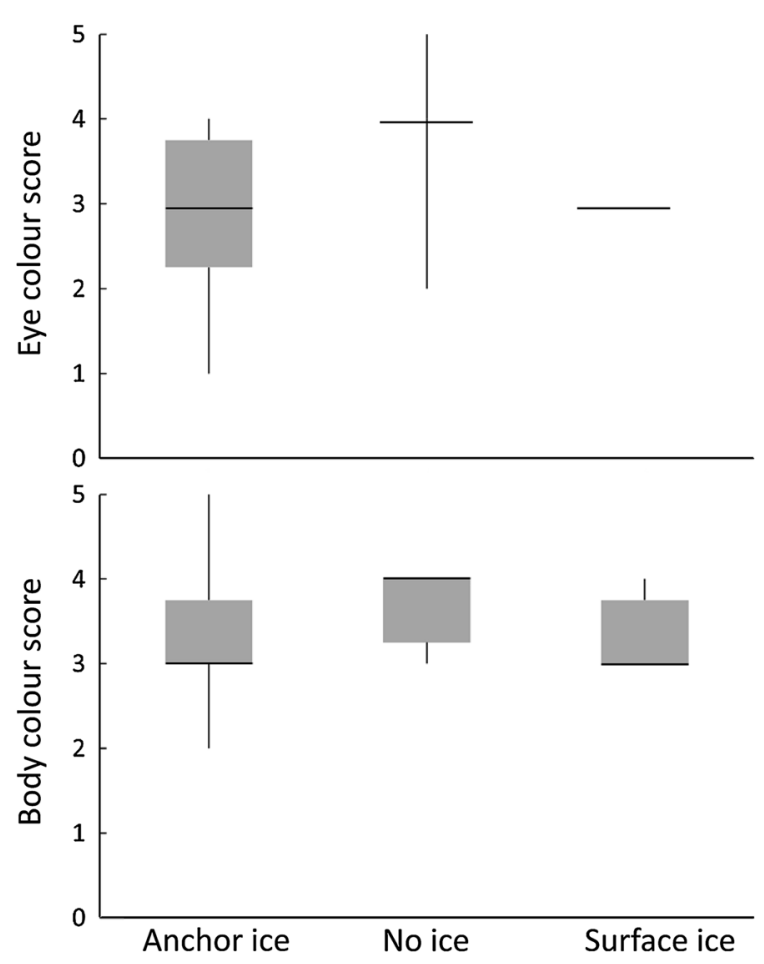

Fig. 4 Juvenile brown trout (Salmo trutta) under different simulated winter conditions in an artificial stream. Eye (upper panel) and body (lower panel) colour scores were recorded $(n=6)$. Horizontal lines indicate median values, grey boxes the 1 st and 3rd quartiles and whiskers the minimum and maximum values

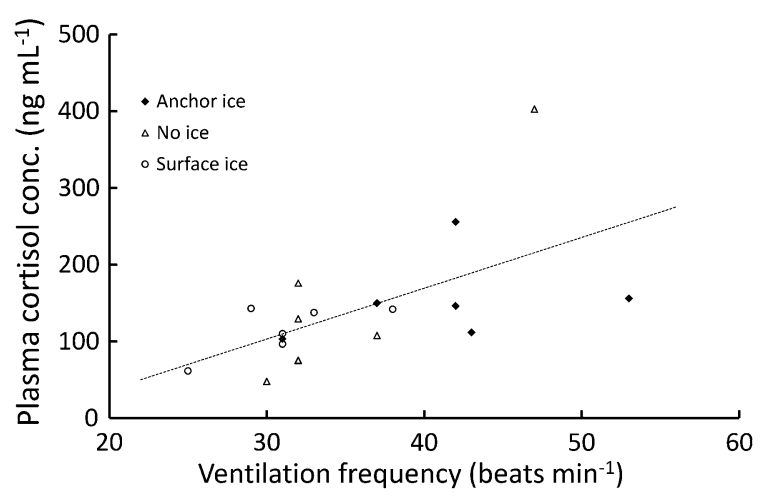

Fig. 5 Relationship between plasma cortisol concentration and ventilation frequency in juvenile brown trout (Salmo trutta) under simulated winter conditions in an artificial stream. Trout were exposed to three treatments where trout were excluded from a bottom shelter (simulating the effect of anchor ice), had access to the bottom shelter (no ice) and had access both to the bottom shelter and partial ice cover (surface ice). The dashed line indicates the relationship between plasma cortisol concentration and ventilation frequency when pooling data from all treatments $(n=18)$ 
juvenile brown trout. Specifically, trout excluded from the instream wood shelter in the treatment that simulated the effect of anchor ice had higher ventilation frequency than those that had access to the shelter. Ventilation frequency is a sensitive measure to perceived predation risk (Hawkins et al., 2004; Brown et al., 2005; Hawkins et al., 2007), and fish without overhead shelter increase their oxygen consumption presumably to increase predator vigilance (Millidine et al., 2006). Moreover, ventilation frequency increases rapidly as a response to a stressor (Barreto $\&$ Volpato, 2004) and seems largely unaffected by social interactions (Watz et al., 2015). Under experimental winter conditions, Watz et al. (2013) showed that trout under full surface ice cover reduced their ventilation frequency and increased foraging activity, which might lead to an improved energetic balance (Watz et al., 2016). The effect of surface ice (compared to the no ice treatment) was not as strong in the present study, possibly because that the wood bundle provided adequate protection.

When teleost fishes experience stress, plasma cortisol concentrations generally increase dramatically as a primary response (Mommsen et al., 1999). High cortisol levels may increase mortality, and, for example, brown trout with artificially elevated cortisol levels have reduced overwinter survival rates (Midwood et al., 2015). Lack of winter shelters has been shown to elevate metabolic rates, which has been suggested to be sustained by cortisol (Millidine et al., 2006). These elevated metabolic rates can lead to depletion of energy stores (Biro et al., 2004), one major cause of mortality in overwintering fish (Hurst, 2007). In the present study, there was a strong positive correlation between ventilation frequency and cortisol level (Barton \& Schreck, 1987), but this correlation does not necessarily indicate a cause and effect relationship. Instead, catecholamines likely modulate ventilation frequency and not corticosteroids (Kinkead et al., 1993). Thus, it seems likely that both elevated cortisol concentration and ventilation frequency were responses to the same stressor, but the elevated ventilation frequency was not a direct result of increasing plasma cortisol concentrations.

Increased acute predation risk has previously been shown to result in elevated cortisol levels (e.g., Rehnberg \& Schreck, 1987; Barcellos et al., 2007). Other studies show that also oxygen consumption is influenced by predation risk (e.g., Metcalfe et al., 1987; Hawkins et al., 2004). Few studies, however, report the effects of predation risk on both cortisol levels and oxygen consumption. Woodley \& Peterson (2003) found that in longnose killifish (Fundulus majalis), visual contact with its predator sand seatrout (Cynoscion arenarius) increased plasma cortisol concentration and oxygen consumption, which led to reduced growth. On the other hand, Sanches et al. (2015) exposed Nile tilapia (Oreochromis niloticus) to chemical alarm cues and these fish markedly increased ventilation frequency and reduced feeding activity, but the effect on plasma cortisol concentration was weak. In my study, there was a positive correlation between cortisol concentration and ventilation frequency, but despite this relationship, no effect of treatments on mean plasma cortisol concentration was found. The effects of perceived predation risk on different stress responses probably vary among species, and, in particular, effects on cortisol levels may be small in brown trout (Lepage et al., 2001). Nonetheless, individual plasma cortisol concentrations varied greatly, and were all high compared to those in other studies of unstressed or mildly stressed brown trout (Flodmark et al., 2002; Brelin et al., 2005). Mean cortisol concentration was instead roughly the same as those reported for trout after being subjected to handling or confinement stress (Norris et al., 1999; Ruane et al., 1999; Barton, 2000). In the present study, trout were netted from the holding tank to the experimental arena approximately $20 \mathrm{~h}$ before the trials. This time may have been too short for a complete recovery to baseline levels, but it should have reduced handling-induced cortisol elevation substantially (Pickering \& Pottinger, 1989). Moreover, it is possible that being transferred from a social environment in a large holding tank to being solitary in the experimental arena affected the overall stress level (Schleuter et al., 2007) because of an increased need for predator vigilance when not being in a group (Roberts, 1996).

In salmonids, darkening of eye and body communicates submission in subordinates to avoid conflicts with dominant fish and has been used as a sign of social stress (O'Connor et al., 1999; Höglund et al., 2000; Suter \& Huntingford, 2002). Darkening has been suggested to reflect also a fish's general stress level (Freitas et al., 2014). In some species, a positive relationship between cortisol concentration and colour 
has been demonstrated, for example, Senegalese sole (Solea senegalensis) (Ruane et al., 2005) and Nile tilapia (Oreochromis niloticus) (Endo et al., 2002). This relationship has also been found in salmonids (Iger et al., 1995; Höglund et al., 2000), but for social fish, such as juvenile salmonids, it is difficult to discriminate between social and non-social stress, because fish that experience non-social stress tend to become subordinates, increasing the level of social stress (Gilmour et al., 2005). The trout in the present study were tested individually, and no correlations between colour and cortisol concentration or ventilation frequency were found, indicating that colour might be an unreliable indicator of non-social stress, at least in salmonids.

\section{Conclusion}

Access to shelter in low embedded bottom substrates with stream wood is a key habitat factor for overwintering juvenile salmonids (Finstad et al., 2007; Stickler et al., 2008; Linnansaari et al., 2009), and in its absence, surface ice may provide overhead cover (Linnansaari et al., 2009; Watz et al., 2016). This study showed that, when denied access to winter shelter, juvenile brown trout display a stress response, mainly by increasing their ventilation frequency. Many European rivers and streams are highly degraded (Schmutz et al., 2016), and in these structurally simple watercourses hydropower regulation that reduces surface ice and increases anchor ice formation may lead to increased stress and consequently reduce overwinter survival rates.

Acknowledgements This work was funded by The Royal Swedish Academy of Agriculture and Forestry and Carl-Fredrik von Horn's Foundation (GFS2015-0085). I thank Gammelkroppa Lax AB for kindly providing me with trout for the experiment, Ann Erlandsson for assistance with the cortisol ELISA and Olle Calles, Larry Greenberg, Daniel Nyqvist and three anonymous reviewers for comments on an earlier version of this manuscript. This study was approved by the Animal Ethical Board of Sweden (reference 88-2013).

Open Access This article is distributed under the terms of the Creative Commons Attribution 4.0 International License (http:// creativecommons.org/licenses/by/4.0/), which permits unrestricted use, distribution, and reproduction in any medium, provided you give appropriate credit to the original author(s) and the source, provide a link to the Creative Commons license, and indicate if changes were made.

\section{References}

Barcellos, L. J. G., F. Ritter, L. C. Kreutz, R. M. Quevedo, L. B. da Silva, A. C. Bedin, J. Finco \& L. Cericato, 2007. Wholebody cortisol increases after direct and visual contact with a predator in zebrafish, Danio rerio. Aquaculture 272: 774-778.

Barreto, R. E. \& G. L. Volpato, 2004. Caution for using ventilatory frequency as an indicator of stress in fish. Behavioural Processes 66: 43-51.

Barton, B. A., 2000. Salmonid fishes differ in their cortisol and glucose responses to handling and transport stress. North American Journal of Aquaculture 62: 12-18.

Barton, B. A., 2002. Stress in fishes: a diversity of responses with particular reference to changes in circulating corticosteroids. Integrative and Comparative Biology 42: 517-525.

Barton, B. A. \& G. K. Iwama, 1991. Physiological changes in fish from stress in aquaculture with emphasis on the response and effects of corticosteroids. Annual Review of Fish Diseases 1: 3-26.

Barton, B. A. \& C. B. Schreck, 1987. Metabolic cost of acute physical stress in juvenile steelhead. Transactions of the American Fisheries Society 116: 257-263.

Biro, P. A., A. E. Morton, J. R. Post \& E. A. Parkinson, 2004. Over-winter lipid depletion and mortality of age-0 rainbow trout (Oncorhynchus mykiss). Canadian Journal of Fisheries and Aquatic Sciences 61: 1513-1519.

Brelin, D., E. Petersson \& S. Winberg, 2005. Divergent stress coping styles in juvenile brown trout (Salmo trutta). Annals of the New York Academy of Sciences 1040: 239-245.

Bonga, S. W., 1997. The stress response in fish. Physiological Reviews 77: 591-625.

Brown, R. S. \& W. C. Mackay, 1995. Fall and winter movements of and habitat use by cutthroat trout in the Ram River, Alberta. Transactions of the American Fisheries Society 124: 873-885.

Brown, C., C. Gardner \& V. A. Braithwaite, 2005. Differential stress responses in fish from areas of high- and low-predation pressure. Journal of Comparative Physiology B: Biochemical, Systemic, and Environmental Physiology 175: 305-312.

Brown, R. S., W. A. Hubert \& S. F. Daly, 2011. A primer on winter, ice, and fish: what fisheries biologists should know about winter ice processes and stream-dwelling fish. Fisheries 36: 8-26.

Endo, M., C. Kumahara, T. Yoshida \& M. Tabata, 2002. Reduced stress and increased immune responses in Nile tilapia kept under self-feeding conditions. Fisheries Science 68: 253-257.

Espelid, S., G. B. Løkken, K. Steiro \& J. Bøgwald, 1996. Effects of cortisol and stress on the immune system in Atlantic salmon (Salmo salar L.). Fish \& Shellfish Immunology 6: 95-110.

Finstad, A. G., S. Einum, T. Forseth \& O. Ugedal, 2007. Shelter availability affects behaviour, size-dependent and mean growth of juvenile Atlantic salmon. Freshwater Biology 52: $1710-1718$.

Flodmark, L. E. W., H. A. Urke, J. H. Halleraker, J. V. Arnekleiv, L. A. Vøllestad \& A. B. S. Poléo, 2002. Cortisol and 
glucose responses in juvenile brown trout subjected to a fluctuating flow regime in an artificial stream. Journal of Fish Biology 60: 238-248.

Freitas, R. H. A., C. A. Negrão, A. K. C. Felício \& G. L. Volpato, 2014. Eye darkening as a reliable, easy and inexpensive indicator of stress in fish. Zoology 117: 179-184.

Gebre, S., K. Alfredsen, L. Lia, M. Stickler \& E. Tesaker, 2013. Review of ice effects on hydropower systems. Journal of Cold Regions Engineering 27: 196-222.

Gilmour, K. M., J. D. DiBattista \& J. B. Thomas, 2005. Physiological causes and consequences of social status in salmonid fish. Integrative and Comparative Biology 45: 263-273.

Hansen, E. H. \& F. J. Rahel, 2015. Fish energy use among fluctuating and constant thermal regimes simulating winter conditions in rivers. Transactions of the American Fisheries Society 144: 990-997.

Hawkins, L. A., J. D. Armstrong \& A. E. Magurran, 2004. Predator-induced hyperventilation in wild and hatchery Atlantic salmon fry. Journal of Fish Biology 65: 88-100.

Hawkins, L. A., A. E. Magurran \& J. D. Armstrong, 2007. Innate abilities to distinguish between predator species and cue concentration in Atlantic salmon. Animal Behaviour 73: 1051-1057.

Hedger, R. D., T. F. Næsje, P. Fiske, O. Ugedal, A. G. Finstad \& E. B. Thorstad, 2013. Ice-dependent winter survival of juvenile Atlantic salmon. Ecology and Evolution 3: 523-535.

Höglund, E., P. H. Balm \& S. Winberg, 2000. Skin darkening, a potential social signal in subordinate arctic charr (Salvelinus alpinus): the regulatory role of brain monoamines and pro-opiomelanocortin-derived peptides. Journal of Experimental Biology 203: 1711-1721.

Hurst, T. P., 2007. Causes and consequences of winter mortality in fishes. Journal of Fish Biology 71: 315-345.

Huusko, A., L. Greenberg, M. Stickler, T. Linnansaari, M. Nykanen, T. Vehanen, S. Koljonen, P. Louhi \& K. Alfredsen, 2007. Life in the ice lane: the winter ecology of stream salmonids. River Research and Applications 23: 469-491.

Ibarra-Zatarain, Z., E. Fatsini, S. Rey, O. Chereguini, I. Martin, I. Rasines, C. Alcaraz \& N. Duncan, 2016. Characterization of stress coping style in Senegalese sole (Solea senegalensis) juveniles and breeders for aquaculture. Royal Society Open Science 3: 160495.

Iger, Y., P. H. M. Balm, H. A. Jenner \& S. E. W. Bonga, 1995. Cortisol induces stress-related changes in the skin of rainbow trout (Oncorhynchus mykiss). General and Comparative Endocrinology 97: 188-198.

Jakober, M. J., T. E. McMahon, R. F. Thurow \& C. G. Clancy, 1998. Role of stream ice on fall and winter movements and habitat use by bull trout and cutthroat trout in Montana headwater streams. Transactions of the American Fisheries Society $127:$ 223-235.

Kinkead, R., S. Aota, S. F. Perry \& D. J. Randall, 1993. Propranolol impairs the hyperventilatory response to acute hypercapnia in rainbow trout. Journal of Experimental Biology 175: 115-126.

Lepage, O., Ø. Øverli, E. Petersson, T. Järvi \& S. Winberg, 2001. Differential stress coping in wild and domesticated sea trout. Brain, Behavior and Evolution 56: 259-268.
Linnansaari, T. \& R. A. Cunjak, 2010. Patterns in apparent survival of Atlantic salmon (Salmo salar) parr in relation to variable ice conditions throughout winter. Canadian Journal of Fisheries and Aquatic Sciences 67: 1744-1754.

Linnansaari, T. \& R. A. Cunjak, 2013. Effects of ice on behaviour of juvenile Atlantic salmon (Salmo salar). Canadian Journal of Fisheries and Aquatic Sciences 70: 1488-1497.

Linnansaari, T., K. Alfredsen, M. Stickler, J. V. Arnekleiv, A. Harby \& R. A. Cunjak, 2009. Does ice matter? Site fidelity and movements by Atlantic salmon (Salmo salar L.) parr during winter in a substrate enhanced river reach. River Research and Applications 25: 773-787.

McCormick, S. D., J. M. Shrimpton, J. B. Carey, M. F. O'dea, K. E. Sloan, S. Moriyama \& B. T. Björnsson, 1998. Repeated acute stress reduces growth rate of Atlantic salmon parr and alters plasma levels of growth hormone, insulin-like growth factor I and cortisol. Aquaculture 168: 221-235.

Metcalfe, N. B., F. A. Huntingford \& J. E. Thorpe, 1987. The influence of predation risk on the feeding motivation and foraging strategy of juvenile Atlantic salmon. Animal Behaviour 35: 901-911.

Midwood, J. D., M. H. Larsen, M. Boel, K. Aarestrup \& S. J. Cooke, 2015. An experimental field evaluation of winter carryover effects in semi-anadromous brown trout (Salmo trutta). Journal of Experimental Zoology Part A: Ecological Genetics and Physiology 323: 645-654.

Millidine, K. J., J. D. Armstrong \& N. B. Metcalfe, 2006. Presence of shelter reduces maintenance metabolism of juvenile salmon. Functional Ecology 20: 839-845.

Millidine, K. J., N. B. Metcalfe \& J. D. Armstrong, 2008. The use of ventilation frequency as an accurate indicator of metabolic rate in juvenile Atlantic salmon (Salmo salar). Canadian Journal of Fisheries and Aquatic Sciences 65: 2081-2087.

Mommsen, T. P., M. M. Vijayan \& T. W. Moon, 1999. Cortisol in teleosts: dynamics, mechanisms of action, and metabolic regulation. Reviews in Fish Biology and Fisheries 9: 211-268.

Norris, D. O., S. Donahue, R. M. Dores, J. K. Lee, T. A. Maldonado, T. Ruth \& J. D. Woodling, 1999. Impaired adrenocortical response to stress by brown trout, Salmo trutta, living in metal-contaminated waters of the Eagle River, Colorado. General and Comparative Endocrinology 113: $1-8$.

O'Connor, K. I., N. B. Metcalfe \& A. C. Taylor, 1999. Does darkening signal submission in territorial contests between juvenile Atlantic salmon, Salmo salar? Animal Behaviour 58: $1269-1276$.

Pickering, A. D. \& T. G. Pottinger, 1989. Stress responses and disease resistance in salmonid fish: effects of chronic elevation of plasma cortisol. Fish Physiology and Biochemistry 7: 253-258.

Pinedo-Gil, J., A. Tomás-Vidal, A. M. Larrán-García, C. Tomás-Almenar, M. Jover-Cerdá, M. Á Sanz-Calvo \& A. B. Martín-Diana, 2016. Enhancement of quality of rainbow trout (Oncorhynchus mykiss) flesh incorporating barley on diet without negative effect on rearing parameters. Aquaculture International. Online First1-19.

Prowse, T. D., 2001. River-ice ecology. II: biological aspects. Journal of Cold Regions Engineering 15: 17-33. 
Rehnberg, B. G. \& C. B. Schreck, 1987. Chemosensory detection of predators by coho salmon (Oncorhynchus kisutch): behavioural reaction and the physiological stress response. Canadian Journal of Zoology 65: 481-485.

Roberts, G., 1996. Why individual vigilance declines as group size increases. Animal Behaviour 51: 1077-1086.

Ruane, N. M., S. E. Wendelaar Bonga \& P. H. M. Balm, 1999. Differences between rainbow trout and brown trout in the regulation of the pituitary-interrenal axis and physiological performance during confinement. General and Comparative Endocrinology 115: 210-219.

Ruane, N. M., P. Makridis, P. H. M. Balm \& M. T. Dinis, 2005. Skin darkness is related to cortisol, but not MSH, content in post-larval Solea senegalensis. Journal of Fish Biology 67: 577-581.

Sanches, F. H. C., C. A. Miyai, C. F. Pinho-Neto \& R. E. Barreto, 2015. Stress responses to chemical alarm cues in Nile tilapia. Physiology \& Behavior 149: 8-13.

Schleuter, D., S. Haertel-Borer, P. Fischer \& R. Eckmann, 2007. Respiration rates of Eurasian perch Perca fluviatilis and ruffe: lower energy costs in groups. Transactions of the American Fisheries Society 136: 43-55.

Schmutz, S., P. Jurajda, S. Kaufmann, A. W. Lorenz, S. Muhar, A. Paillex, M. Poppe \& C. Wolter, 2016. Response of fish assemblages to hydromorphological restoration in central and northern European rivers. Hydrobiologia 769: 67-78.

Stickler, M. \& K. T. Alfredsen, 2009. Anchor ice formation in streams: a field study. Hydrological Processes 23: 2307-2315.

Stickler, M., E. C. Enders, C. J. Pennell, D. Cote, K. Alfredsen \& D. A. Scruton, 2008. Stream gradient-related movement and growth of Atlantic salmon parr during winter. Transactions of the American Fisheries Society 137: 371-385.

Suter, H. C. \& F. A. Huntingford, 2002. Eye colour in juvenile Atlantic salmon: effects of social status, aggression and foraging success. Journal of Fish Biology 61: 606-614.
Timalsina, N. P., J. Charmasson \& K. T. Alfredsen, 2013. Simulation of the ice regime in a Norwegian regulated river. Cold Regions Science and Technology 94: 61-73.

Ugedal, O., T. F. Næsje, E. B. Thorstad, T. Forseth, L. M. Saksgård \& T. G. Heggberget, 2008. Twenty years of hydropower regulation in the River Alta: long-term changes in abundance of juvenile and adult Atlantic salmon. Hydrobiologia 609: 9-23.

Valdimarsson, S. K. \& N. B. Metcalfe, 2001. Is the level of aggression and dispersion in territorial fish dependent on light intensity? Animal Behaviour. 61: 1143-1149.

Velasco-Santamaría, Y. \& P. Cruz-Casallas, 2007. Methodology for determination of plasma cortisol in fish using competitive enzyme-linked immunosorbent assay (ELISA). Revista MVZ Córdoba 12: 869-877.

Watz, J., E. Bergman, J. J. Piccolo \& L. Greenberg, 2013. Effects of ice cover on the diel behaviour and ventilation rate of juvenile brown trout. Freshwater Biology 58: 2325-2332.

Watz, J., J. Piccolo, E. Bergman \& L. Greenberg, 2014. Day and night drift-feeding by juvenile salmonids at low water temperatures. Environmental Biology of Fishes 97: 505-513.

Watz, J., E. Bergman, O. Calles, Å. Enefalk, S. Gustafsson, A. Hagelin, P. A. Nilsson, J. R. Norrgård, D. Nyqvist, E. M. Österling, J. J. Piccolo, L. D. Schneider, L. Greenberg \& B. Jonsson, 2015. Ice cover alters the behavior and stress level of brown trout Salmo trutta. Behavioral Ecology 26: 820-827.

Watz, J., E. Bergman, J. J. Piccolo \& L. Greenberg, 2016. Ice cover affects the growth of a stream-dwelling fish. Oecologia 181: 299-311.

Woodley, C. M. \& M. S. Peterson, 2003. Measuring responses to simulated predation threat using behavioral and physiological metrics: the role of aquatic vegetation. Oecologia 136: $155-160$. 